Sobral, F., Chambel, M. J., Castanheira, F., \& Cesário, F. (2019). A psychometric assessment of a human resources practice measure for temporary agency workers. Spanish Journal of Psychology, 22, [e16].

https://doi.org/10.1017/sjp.2019.18

\title{
A psychometric assessment of a HR practice measure for temporary agency workers
}

\begin{abstract}
Studies have proposed and validated several measures that evaluate employee's perceptions of the human resources practices (HRP). However, given the changes occurring in the labor market, there is a need to develop a measure specially adapted to contingent workers. These workers have a specific type of employment relationship and distinct needs and concerns. Thus, this study assesses an HRP system scale that was administered to temporary agency workers (TAW) to examine the scale's response process, internal structure and relation to other variables (i.e., affective commitment). The measure was administered to 4551 Portuguese TAW. The Messick's validation framework (1995) was use and two sectors were compared. Descriptive analyses, scale reliabilities, item characteristics, exploratory, confirmatory, and multiple group analyses demonstrated that the measure had good psychometric properties. Moreover, there were positive correlations between the HRP scale and commitment. The results contribute to a better understanding of managing TAW's in agencies and client companies. HRP are a valuable method for "communicating" with these workers, who are then able to recognize and respond to the investment. This is the first study to develop and assess the psychometric properties of an HRP system measure for TAW and to cross-validate it with workers' affective commitment towards both companies that are involved in this employment relation.
\end{abstract}

Keywords: Human Resource Practices; Contingent Work; Temporary Agency Workers; Affective Commitment; Psychometric Assessment. 
Sobral, F., Chambel, M. J., Castanheira, F., \& Cesário, F. (2019). A psychometric assessment of a human resources practice measure for temporary agency workers. Spanish Journal of Psychology, 22, [e16].

https://doi.org/10.1017/sjp.2019.18

\section{Introduction}

Since the 1980's, human resources (HR) management has been discussed, as it then became part of the work relations' lexis (Boxall \& Purcell, 2011). Armstrong (2014) defines HR as a planned method for managing an organization's most valuable resources: the people who contribute to the company's goals and success. Through HR management, a company can provide development opportunities and implement processes that can increase worker's retention, commitment, and motivation (Nishii \& Wright, 2008; Armstrong, 2014). According to social exchange theory (Blau, 1964), HR management is often the method for employer and employee communication (Bowen and Ostroff, 2004). By sending certain messages, which may be from an HR Practice (HRP) system, companies can connect with workers, emphasize their importance and persuade them to respond in the same direction and present the organizations' values and expectations (e.g., Den Hartog, Boon, Verburg, \& Croon, 2013; Nishii \& Wright, 2008).

Earlier research demonstrated that HRP are positively related to affective commitment (AC) and workers' and firm's performance (e.g., Takeuchi, Lepak, Wang, \& Takeuchi 2007; Zacharatos, Barling, \& Iverson, 2005). However, these reactions are not solely due to the presence of an HRP. Nishii and Wright (2008) showed that it is possible to outline an HRP's intended (i.e., the practice's design), actual (i.e., the practice's delivery and implementation), and perceived (i.e., the employee's interpretation of the practices) practices. Thus, HRP's intended and actual effects primarily result in employee's perceptions (Nishii \& Wright, 2008). A good fit between practices and individual characteristics (i.e., values, goals, and expectations) can increase the effectiveness of a specific HRP system (e.g., Den Hartog, et al., 2013).

Additionally, HR management strategies are not immune to the social context (Boxall and Purcell, 2011; Guest, 2017). Currently, HR departments are expected to operate as a 
Sobral, F., Chambel, M. J., Castanheira, F., \& Cesário, F. (2019). A psychometric assessment of a human resources practice measure for temporary agency workers. Spanish Journal of Psychology, 22, [e16].

https://doi.org/10.1017/sjp.2019.18

"business within a business" and in structural alignment with the organization's model

(Ulrich, Younger, \& Brockbank, 2008), contributing to the company's financial performance (and establishing a stable and sustainable production, while increasing competition, versatility, and work flexibility (De Jong, 2014).

Numerical, functional and mental flexibility are key concepts in work relations. The worker's perspectives combined with competitive pressure forced companies to assume more flexible work policies (De Jong, 2014). However, in contrast to the 80's and 90's, currently using contingent work may not be connected to specific increases or demands (Zimmerman, Gavrilova-Aguilar, \& Cullum, 2013). Indeed, contingent workers perform their tasks alongside direct employees in a wide range of sectors and activities inside the market (De Cuyper, De Witte, \& Emmerk, 2011; Buch, Kuvaas, \& Dysvik, 2010). Furthermore, statistics confirm that the numbers of contingent workers have grown since the end of the last century (Eurostat, 2016; OECD, 2016).

Labor flexibility's growth and development also impacted the configuration of contingent work. From the existing contingent work formats, temporary staffing agencies have the most complex work arrangement (Sobral, Chambel, \& Castanheira, 2016). Temporary agency workers (TAW) are in a three-way relationship and are capable of creating 'dual allegiances' (Bonet, Cappelli, \& Hamori, 2013). They establish work relations with the temporary agency, with which they have a formal contract, and the client company, with whom they actually work (Sobral, et al., 2016; Sobral, Lopes, Chambel, \& Castanheira, 2015). Given this reality, several studies (e.g., Zimmerman, et al., 2013) have indicated a need to adjust and adapt academic representations of labor relations to the present context.

Integrating contingent workers presents a challenge for HR management. It is important to understand how companies can effectively integrate these workers into their workforce (Jing and Wang, 2018; Zimmerman, et al., 2013) and the HRPs that can be applied to match their 
Sobral, F., Chambel, M. J., Castanheira, F., \& Cesário, F. (2019). A psychometric assessment of a human resources practice measure for temporary agency workers. Spanish Journal of Psychology, 22, [e16]. https://doi.org/10.1017/sjp.2019.18

needs. Contingent work is often associated with uncertainty and insecurity, which, in turn, is related with negative outcomes (Höge, Sora, Weber, Peiró, \& Caballer, 2015). Moreover, most contingent workers accepted their positions with a goal of obtaining a permanent position inside the client company (e.g.,Sobral, et al., 2016; Sobral, et al., 2015). Therefore, these workers do not choose to be contingent. However, previous research has shown that TAW reciprocate and value the investments that are made by their organizations, which may lead them to respond in accord (e.g., Buch, et al. 2010; Chambel \& Sobral, 2011; Chambel, Castanheira, \& Sobral, 2016; Jing and Wang, 2018). Voluntary or involuntary contingent work situations have an influence on the worker's internal employment prospects (within the current employee) and the external labor market (finding a job elsewhere; De Cuyper, et al., 2011). Hence, the HRP that companies implement may play a crucial role in responding to TAW's specific needs. Like recently underlined by Guest (2017), the context variation can make certain HRP more relevant than others. Meaning that the national context, the organizational specificities and arrangements (i.e., sector, size or external competitive environment), and the individual characteristics have impact in the way practices are delivered by the company and received by the workers. However, according with the research team knowledge, there are no HRP measures that have been adapted or psychometrically assessed for contingent workers, and specifically TAW.

Several empirically validated HRP measures have been developed in the context of standard employment. Zacharatos and colleagues (2005) developed a 68-items scale that evaluated high-performance work practices and measured employment security, selective hiring, training, decentralized decision making, status distinctions, information sharing, contingent compensation, leadership, high-quality work, and management practices. Then, Takeuchi and colleagues (2007) developed a 21-item scale that was also for high-performance work systems and measured workers' autonomy, the selection process, training and development 
Sobral, F., Chambel, M. J., Castanheira, F., \& Cesário, F. (2019). A psychometric assessment of a human resources practice measure for temporary agency workers. Spanish Journal of Psychology, 22, [e16].

https://doi.org/10.1017/sjp.2019.18

opportunities, performance appraisal, and the compensation system. The HRP was described as a system in both studies.

Although both scales have been validated and recognized by the academic community, none have been tested with contingent workers.

The current study builds on Zacharatos (et al., 2005) and Takeuchi's research (et al., 2007) to develop and psychometrically validate an HRP scale that was adjusted for the TAW population. These authors greatly inspired the scale's item construction and measurement of the HRP system. Furthermore, because each HRP is not independent (Chambel, et al., 2016), it is examined how TAW's perceive HRP regardless of the company provides the practices. It is believed that the agency and the client are jointly responsible for the HRP system; thus, TAW's overall perceptions were measured. Buch (et al., 2010) highlighted that behaviors toward one company may depend on the benefits that are exchanged with the other and vice versa.

To obtain the final 20-item scale that measured TAW's perceptions of the HRP system, were employed several steps. First, the research team interviewed agencies and client companies HR managers to discuss the practices that were included in Zacharatos (et al., 2005) and Takeuchi's (et al., 2007) scales. Second, the interviews were analyzed to understand which practices are used to manage these workers. Most HR managers agreed that there were four central practices: the recruitment process (i.e., the fit between employees and their work environment; items 1 through 4, see Table 2), socialization (i.e., identifying with the organization's context; items 5 through 8, see Table 2), training and development (employability inside and outside the current company) opportunities (i.e., skill empowerment; items 9 through 16, in which items 9, 11, 13 and 14 refer to training that can develop external employability; and items $10,12,15$ and 16 refer to training that can develop external employability, see Table 2), and performance appraisal (i.e., a clear and fair 
Sobral, F., Chambel, M. J., Castanheira, F., \& Cesário, F. (2019). A psychometric assessment of a human resources practice measure for temporary agency workers. Spanish Journal of Psychology, 22, [e16]. https://doi.org/10.1017/sjp.2019.18

evaluation method; items 17 through 20, see Table 2). Third, items were developed to measure each practice. Items that referred to the recruitment process and performance appraisal were obtained from Zacharatos (et al., 2005) and Takeuchi’s scales (et al., 2007). However, there were several identified practices that the HR managers identified that were not included in those scales, specifically socialization and training/employability development. The items that measured training to promote TAW's employability (e.g., acquiring transferable skills that can be used inside or outside the current organization) were influenced by these authors as well as Chambel and Sobral's items (2011). The socialization items were based on Ashforth and Sak's research (1996). These authors suggested that socialization allows newcomers to identify with the organization's values and norms and learn the organizational culture.

Moreover, certain practices, including employment security and decentralized decisionmaking, were not useful in this work context. In addition, the compensation system was not transversal to all sectors and functions that were included in the final item pool.

Finally, the Messicks' validation framework (1995) was used to assess the psychometrics of the scale. Specifically, this study followed steps for analyzing the response process, internal structure, and relationships to other variables. To examine the scale's 'relationship with other variables,' it was tested the relationship between TAW's perceptions of HRP and their affective commitment (AC) toward the agency and client companies. Because AC is based on an emotional liaison and identification with organizational values and goals (Chambel, et al., 2016), when companies want to achieve competitive performance, they must invest a critical outcome like worker's AC . Consequently, it was important to determine whether perceptions of the HRP system perception could predict TAW's AC. In addition, because the literature already demonstrated that TAW's create two different ACs, one with the agency and another with the client company (Buch et al., 2010; Sobral, et al., 2016; Sobral, et al., 2015), both 
Sobral, F., Chambel, M. J., Castanheira, F., \& Cesário, F. (2019). A psychometric assessment of a human resources practice measure for temporary agency workers. Spanish Journal of Psychology, 22, [e16].

https://doi.org/10.1017/sjp.2019.18

ACs were considered in the current study.

\section{Method}

\section{Sample}

The sample consisted of TAW $(\mathrm{N}=4551)$ from several temporary employment agencies that were operating in Portugal. The sample included workers from services (i.e., commerce, hospitality, catering, and transports; 68.8\%) and industry (i.e., manufacturing, heavy machinery handling, storage, and construction; 30.8\%), who had different functions. These participants all worked for clients who employed TAW to adapt to current market needs. This decision enabled the organizations to adjust to fluctuations in client requests or services. The respondents completed an online questionnaire. Data were collected using SurveyMonkey, which is a commercial survey service. The agencies emailed a link to the survey to their workers. This email included a message from the research team that explained the purpose of the project, the voluntary nature of participation, and the procedure. Because participation was voluntary and anonymous, participants did not sign an informed consent form. Participant's response rates ranged from $42 \%$ to $58 \%$.

For demographic characteristics, women constituted $53.5 \%$ of the sample and the average age was approximately 31 years old. The distribution by age group was: $50.9 \%$ were less than 29 years old; $33.9 \%$ were between 30 and 39 years old; $11.9 \%$ were between 40 and 49 years old; and 3.3\% were more than 50 years old. Participant's academic qualifications included: 8.5\% had up to 9th grade; $20.0 \%$ completed secondary school; $30.9 \%$ attended the university; $17.7 \%$ graduated; and $23 \%$ completed postgraduate studies. Almost one-quarter of the participants were students (24\%). Most of the sample reported that this was their only job (91.1\%) and that their previously job situation was unemployment (51.6\%). Participant's agency tenure distribution included: $22.1 \%$ had less than 3 months; 20\% had between 3 and 6 months; $13 \%$ had 6 to 9 months; $11 \%$ had 9 months to a year; $30.3 \%$ had 1 to 5 years; $2.6 \%$ 
Sobral, F., Chambel, M. J., Castanheira, F., \& Cesário, F. (2019). A psychometric assessment of a human resources practice measure for temporary agency workers. Spanish Journal of Psychology, 22, [e16].

https://doi.org/10.1017/sjp.2019.18

had 5 to 10 years; and $.8 \%$ had more than 10 years. For tenure distribution in the client company, $21.4 \%$ had less than 3 months; $19 \%$ had 3 to 6 months; $13 \%$ had 6 to 9 months; $11 \%$ had 9 to 13 months; $8.6 \%$ had 13 to 18 months; and $26.9 \%$ had more than 18 months.

\section{Measures}

Perceptions of HRP. Perceptions of the HRP system was measured using a 20 item scale that measured TAW's socialization, recruitment, training (i.e., promotion of internal and external employability), and performance appraisal (see Table 2). The items were answered on 7-point Likert-type rating scale that ranged from "I strongly disagree" (1) to "I strongly agree" (7). AC. TAW's AC toward the agency and the client company was measured using a Portuguese version of Meyer, Allen, \& Smith's scale (1993). Example items included, “I would be happy if I developed the rest of my career in this company," and "I do not feel emotionally attached to this company" (reverse scored). The items were answered on 7-point Likert-type rating scale that ranged from "I strongly disagree" (1) to "I strongly agree" (7). This scale had already been translated, adapted and tested with Portuguese TAW (Chambel, et al., 2016; Chambel \& Sobral, 2011).

\section{Statistical procedures}

This study followed Messick's data analysis steps (1995) for assessing the validity of a construct. First, in line with the author's conceptualization, a correct response process was used to confirm the data integrity. Thus, the response process was designed to eliminate or at least maximally control for all potential sources of error that were connected to administering the instrument (Downing, 2003). The data collection and analysis process used clear instructions and disclosed the research aims, team, and technical procedures' to increase quality assurance. 
Sobral, F., Chambel, M. J., Castanheira, F., \& Cesário, F. (2019). A psychometric assessment of a human resources practice measure for temporary agency workers. Spanish Journal of Psychology, 22, [e16].

Second, it was necessary to ensure the instrument's psychometric characteristics (i.e., the internal structure). This step examined the descriptive statistics, item characteristics (difficulty and discrimination), and scale reliabilities. Additionally, exploratory and confirmatory factor analyses were performed. As stated by Jöreskog (2007), factor analysis does not have to be exclusively exploratory or confirmatory, especially in studies where there are variables of known and unknown composition. Therefore, by cross-validating the results from the exploratory factor analysis, through the conduction of a confirmatory factor analysis on a different data set (e.g. using random split samples), it is possible to obtain more reliable results. Following Gerbing and Hamilton’s (1996) and Jöreskog (2007) recommendation, SPSS was used to randomly split the sample and run an exploratory factor analysis on one sample (50\% of the original sample) as a precursor to the confirmatory factor analysis on the other sample (the remaining $50 \%$ of the original sample).

The exploratory factor analysis was performed with SPSS version 21.0 (SPSS Inc., Chicago, IL, USA). This study followed Takeuchi and colleagues' (2007; see also Zacharatos et al., 2005) procedures to evaluate a uni-dimensional conceptualization of the HRP. A principal axis factor analysis with a single-factor solution was performed. The confirmatory factor analysis was conducted with AMOS version 21.0 (Amos, Chicago, IL, USA). The overall goodness of the fit was based on combinations of several fit indexes. The model had adequate fit to the data when there was a significant chi-square, .90 or higher for the Tucker Lewis (TLI) and fit indices (CFI), .06 or less for the root mean square error of approximation (RMSEA), and .08 or less for the standardized root mean square (SRMR) (Arbuckle, 2003). After the confirmatory factor analysis, it was also tested the model's fit across different sectors (services and industry). First, the baseline model's fit was determined (Byrne, 2010). Then, the baseline model was compared to (a) a fully constrained model, in which all coefficient paths were constrained to be identical in both sectors; and (b) an invariant 
Sobral, F., Chambel, M. J., Castanheira, F., \& Cesário, F. (2019). A psychometric assessment of a human resources practice measure for temporary agency workers. Spanish Journal of Psychology, 22, [e16].

https://doi.org/10.1017/sjp.2019.18

measurement model, in which only the factor loadings for the observed variables were constrained to be identical in both sectors. These procedures were conducting using multiple group analysis, which included both samples $(\mathrm{N}=4551)$.

Finally, to test the relationship between the HRP measure and other variables, it was necessary to perform a correlation analysis between the new and a well-known measure . Thus, the correlation coefficients between the HRP system and TAW's AC (Meyer, et al., 1993) toward the agency and client company were analyzed.

\section{Insert Table 1 about here}

\section{Results}

\section{Response process}

Respondents were assured that their answers were confidential and anonymous. Participants were informed that they would have the opportunity to receive the overall results. These instructions were written on the questionnaire's cover letter. The instructions explained that the questions were directly related to several parts of their daily work, specifically their perceptions of employment relationships. Participants were informed that the questionnaire was not a test and that there were no right or wrong answers. Workers were also assured that the companies would only have access to a final report and not to the raw data, as the data were used exclusively for academic research. The lead researcher's email address was included in the cover letter in addition to a website address where respondents could find more information about the research project, including the involved academic organizations, its goals, outcomes, partners and other researchers included in the process. There was no incentive (cash or otherwise) for participating in this project.

\section{Internal process}


Sobral, F., Chambel, M. J., Castanheira, F., \& Cesário, F. (2019). A psychometric assessment of a human resources practice measure for temporary agency workers. Spanish Journal of Psychology, 22, [e16].

https://doi.org/10.1017/sjp.2019.18

Descriptive statistics (mean, standard deviation, median, and variance) for the HRP scale and both types of AC were calculated and are presented in Table 1. The HRP scale items characteristics, including difficulty and discriminatory power, are presented at Table 2 . The item difficulty showed that TAWs responded using all values on the Likert scale and that 6 and 7 were the most commonly chosen answers (Table 2). For item discrimination, the results indicate that all 20 items were good discriminants, as all values were greater than .40 (Table 2).

\section{Insert Table 2 about here}

An exploratory factor analysis with principal axis factoring that imposed a single-factor solution analyzed TAW's responses on the HRP scale (Table 2). All 20 items had factor loadings of .45 or above, and the eigenvalue was 9.70 and explained $48.48 \%$ of the variance. These results are in accord with (a) Kaiser (1960; in Field, 2013), who establishes that the eigenvalues should be greater than 1; (b) Stevens (2002; in: Field, 2013, pp. 645), who recommends, "interpreting only factor loadings with an absolute value greater than .4 (that explain approximately $16 \%$ of the variance in the variable)"; and (c) Tabachnick and Fidell (2001), who suggested that the minimum acceptable loading is .32 (approximately $10 \%$ of the variance in the variable). In addition, the percent of variance explained by the one-factor solution was very close to $50 \%$. Although there are no strict guidelines for this parameter, it is an acceptable target (Table 2). The HRP scale also had strong internal-consistency reliability with a Cronbach's alpha value of .94 .

These findings are acceptable and comparable to Takeuchi and colleagues' results (2007). The items from their HR system scale had factor loadings of .37 or above that loaded on a single factor, which explained $35.82 \%$ of the variance and had an eigenvalue of 7.88 . 
Sobral, F., Chambel, M. J., Castanheira, F., \& Cesário, F. (2019). A psychometric assessment of a human resources practice measure for temporary agency workers. Spanish Journal of Psychology, 22, [e16].

https://doi.org/10.1017/sjp.2019.18

Moreover, they had a reliability value of .90 , which was similar to Zacharatos and colleagues' study $(\alpha=.89 ; 2005)$.

For the confirmatory factor analysis, the model with one latent factor (i.e., HRP system) had good fit $\left(\chi^{2}(149)=2429.40, \rho<.001 ;\right.$ SRMR $=.06 ;$ CFI $=.93 ;$ TLI $=.91 ;$ RMSEA $=.08 ;$ see Figure 1).

Insert Figure 1 about here

The internal consistency for AC toward the agency and client company were also adequate at .89 and .90 (Table 1).

For the multiple group analysis between the two sectors (industry and services), a separate baseline model was examined for each sub-samples. As shown in Table 3, these two models had acceptable fit to the data. Subsequently, the two sectors were constrained to compare the baseline and fully constrained models. There was a significant difference between the models chi-square values, which indicated a significant decrease in model fit for the fully constrained model (Cheung \& Rensvold, 2002). The baseline multiple group model had acceptable fit $\left(\chi^{2}\right.$ $(298)=5230.98$, p. 000, CFI $=.92 ;$ RMSEA $=.06 ;$ Table 3).

Finally, the baseline model was compared to an invariant measurement model (factor loadings) and there were no differences between the two sectors on the HRP system. The chisquare and CFI differences were not significant, which supports invariance across the two samples (Table 3).

Insert Table 3 about here 
Sobral, F., Chambel, M. J., Castanheira, F., \& Cesário, F. (2019). A psychometric assessment of a human resources practice measure for temporary agency workers. Spanish Journal of Psychology, 22, [e16].

https://doi.org/10.1017/sjp.2019.18

\section{Relationship to other variables}

The results also indicate that there may be different relationships between perceptions of HRP systems and AC for the agency and client company. As expected, the HRP system was positive and significantly related to both types of AC. The correlations ranged from .45 to .54 $(\mathrm{p}<.01 ;$ Table 1$)$.

\section{Discussion}

Increases in contingent work and changes in complexity and configuration reflects a vast shift in the employment landscape. Prior research has indicated that it is important to examine existing ideas, theories, and instruments before beginning new work (Zimmerman, et al., 2013;) that has new rules, expectations, goals, and, most of all, new roles for the involved actors.

The present study responded to this challenge by developing and assessing the psychometric proprieties of a new HRP measure that was specifically designed for TAWs. The measure was developed in line with Messick's (1995) framework for construct validation. For the response process, the data were comprehensively processed. The internal structure of the measure was also acceptable. First, the descriptive analyses and item characteristics confirmed the importance of each item to the measure. Second, consistent with earlier results (Takeuchi, et al., 2007; Zacharatos, et al., 2005), the exploratory and confirmatory factor analyses confirmed a one-factor structure for the overall sample, as well as both sector subsamples (services and industry). The diversity in job sectors was not reflected in TAW's perception of HRP systems. TAW in services and industry sectors had homogeneous interpretations of the four-general HRPs. These findings are important because services and industry are the most representative sectors in hiring TAWs (WEC, 2018). Future studies should replicate this invariance analysis with different sectors to replicate this pattern.

For the last step in Messick's (1995) framework, determining if there is a relation with other 
Sobral, F., Chambel, M. J., Castanheira, F., \& Cesário, F. (2019). A psychometric assessment of a human resources practice measure for temporary agency workers. Spanish Journal of Psychology, 22, [e16]. https://doi.org/10.1017/sjp.2019.18

variables, TAW's perceptions of the HRP system were positively related to both types of AC. This confirms that investing in TAWs can lead to high AC (Chambel, et al., 2016; Chambel \& Sobral, 2011). Further, the shared variance between the HRP system and both ACs was stronger for the client company (.52), than the agency (.45). Consistent with previous outcomes, this shows that (a) TAWs can create two relationship exchanges and affectively connect with both companies (Buch et al., 2010; 2015; Sobral, et al., 2016 ); and (b) TAWs tend to create closer relations with the client company because they hope to obtain a permanent job there (George, Levenson, Finegold, \& Chattopadhyay, 2010).

Overall, the results demonstrate that the practices that are used to create this HRP system are consistent and coherent with the literature and the context. As Cagliano, Caniato, Longoni, and Spina (2014) have suggested, using temporary work may be associated with more than just flexibility, as companies often use this process to select permanent workers. Therefore, the recruitment process is a fundamental step in hiring these workers, which can be maximized through an effective socialization. Socialization is a key practice inside the HRP system, on one hand it allows the return made in the recruitment and training processes, leveraging the potential competitive advantage of human capital; and on the other hand, effectively socialized workers may be more skilled and loyal (Batistič, 2018). A good example of this practice occurs when workers are well integrated and feel that they are fairly treated. When there is distance between contingent workers and others in the workplace, feelings of alienation may occur (Halbesleben \& Clark, 2010). In contrast, fair treatment and support reduces counterproductive behaviors (Bonet, et al., 2013). Another form of TAW alienation is related to the lack of training opportunities (Ulrich, et al., 2008). Training and employability development opportunities, as shown by Chambel \& Sobral (2011), contribute to TAW's feelings of value and support from the organization. Finally, the performance appraisal practice directs workers to the companies' goals by shaping their outcomes in 
Sobral, F., Chambel, M. J., Castanheira, F., \& Cesário, F. (2019). A psychometric assessment of a human resources practice measure for temporary agency workers. Spanish Journal of Psychology, 22, [e16].

https://doi.org/10.1017/sjp.2019.18

accord with defined targets (Takeuchi, et al., 2007). Additionally, if correct feedback is provided, it can help workers to better perform and adjust themselves to the organization.

\section{Implications for policy and research}

Our research has both theoretical and practical implications. First it highlights the need to design empirical studies focused on the workers' perceptions. Previous research as Nishii and Wright (2008) suggested that the variability associated with workers specificities may act as a moderator between HRP and labor variables. In the present research we propose to study as an element of variability the workers contractual typology, namely by focusing on a specific sample of TAW. There are several measures available to evaluate workers' perceptions over the HRP, but none of them in the context of TAW. Therefore, this study is innovative because it developed a measure specifically built for contingent workers in tripartite employment relationships. HRP such as recruitment, socialization, training or performance evaluation gain in this context a new meaning, both by what they incorporate and by the results they intend to bring, once two companies are involved in the development and application of these practices.

The research design is another significant outcome of the current study. In the same vein of previous research (Takeuchi et al,2007 \& Zacharatos et al.;2005), the HRP were considered as a global system and not as a set of isolated procedures within the organizational dynamics. Although recognizing the existence of different themes and fields of action, the appreciation of the HRP as a system offers a more tangible reading over the perceptions made by individuals. Workers do not feel the practices separately from each other, but as a set of interconnected actions working as a cohesive structure.

Additionally, this study confirms the existence of a positive relationship between the perception of the HRP system and the double affective commitment of TAW. This result 
Sobral, F., Chambel, M. J., Castanheira, F., \& Cesário, F. (2019). A psychometric assessment of a human resources practice measure for temporary agency workers. Spanish Journal of Psychology, 22, [e16].

https://doi.org/10.1017/sjp.2019.18

supports the existence of an exchange relationship, even when workers have a contingent contract; and emphasizes that TAW have an overall perception of the investments made in the HR, regardless of the company that executes it (i.e., agency or client company). Also, this study shows that the relationship between the HRP system and the affective commitment with the agency and the client company may be different. In fact, we found aa stronger relationship between the HRP system and the commitment with the client than the commitment with the agency. This evidence supports the claim that TAW's create a closer relationship with the client company, where TAW expect to obtain a permanent or regular contract (George, et al., 2010).

Overall, the results show that the HRP influence each other and, in the case of TAW, even if applied by agency and/or the client company, can be associated with the same HRP system (Chambel, et al., 2016). In addition, the perception that TAW create of each company (i.e., agency and client company), there is a spillover effect due to the relationship between: worker/agency and worker/client company. The perception that each of these company generates in the individual, can spread to the perception that the worker has regarding the other company. By acting together and creating common and complementary strategies for managing TAW, each company can contribute to the success of the other company. In the end, the development of a positive perception over a joined HRP system, will lead to a positive reinforcement of TAW double affective commitment.

\section{Limitations and directions for future research}

First, this study focused on Portuguese TAW and is not representative. Cross-cultural interpretations or generalizations beyond Europe should take caution. Despite this limitation, the present study had a large sample and respondents were from several agencies, client companies, and several professions. Additionally, to the research team knowledge, there are 
Sobral, F., Chambel, M. J., Castanheira, F., \& Cesário, F. (2019). A psychometric assessment of a human resources practice measure for temporary agency workers. Spanish Journal of Psychology, 22, [e16].

https://doi.org/10.1017/sjp.2019.18

no other HRP instruments that were developed and tested with TAWs and validated in different sectors. An important strength of the present study is that it indicates that it is important to examine TAW's HRP perceptions in an employment relationship. Future studies should use this measure with cross-cultural and representative samples. Moreover, this measure should be tested, and, if necessary, adapted, to other contingent workers.

Second, using cross-sectorial and self-report data raises questions about the commonmethod bias. To address this limitation, several methodological recommendations were followed (Podsakoff, MacKenzie, Lee, \& Podsakoff, 2003). Future research should adopt a longitudinal design and explore (a) how TAWs react to this measure over time; and (b) how it relates to other variables beyond AC.

\section{Conclusions}

By examining the most important HRPs in a system, it was possible to identify how these distinct but interrelated practices contribute to communicating that TAWs are important to the company, which may lead them to reciprocate in the same way. This is an important contribution to the literature, not just by adjusting existing conceptions to the labor market's actual configuration; but also because few studies have recommended that HRP's invest in contingent workers. Although these workers are formally temporary, they become part of the company in which they work, as they work together with other employees and pursue the company's goals. TAW's work in client's facilities, and therefore, represent the agencies. TAW's behaviors and attitudes are crucial for agencies and client companies strategies. Consequently, companies should treat them fairly and invest HRP resources in them.

\section{References}

Arbuckle, J.L., (2003). Amos 5.0 update to the amos user's guide. Chicago: SmallWaters. 
Sobral, F., Chambel, M. J., Castanheira, F., \& Cesário, F. (2019). A psychometric assessment of a human resources practice measure for temporary agency workers. Spanish Journal of Psychology, 22, [e16].

https://doi.org/10.1017/sjp.2019.18

Armstrong, M. (2014), A handbook of human resource management practice (1 ${ }^{\text {th }}$ edition). London: Kogan Page.

Ashforth, B. \& Saks, A. (1996). Socialization tactics: Longitudinal effects on newcomer adjustment. Academy of Management Journal, 39(1), 149-178.

Batistič, S. (2018). Looking beyond - socialization tactics: The role of human resource systems in the socialization process. Human Resource Management, 28, 220-233. DOI:10.1016/j.hrmr.2017.06.004

Blau, P. (1964). Power and exchange in social life. New York, NY: John Wiley and Sons. Bonet, R., Cappelli, P., \& Hamori, M. (2013). Labor Market Intermediaries and the New Paradigm for Human Resources. The Academy of Management Annals, 7 (1), 341-392. DOI: $10.1080 / 19416520.2013 .774213$

Bowen, D.E. \& Ostroff, C. (2004). Understanding HRP-firm performance linkages: The role of 'strength' of the HRM system. Academy of Management Review, 29(2), 203-221.

Boxall, P. \& Purcell, J. (2011). Strategy and human resource management $\left(3^{\text {rd }}\right)$. Basingstoke: Palgrave Macmilla.

Buch, R., Kuvaas, B., \& Dysvik, A. (2010). Dual support in contract workers' triangular employment relationships. Journal of Vocational Behavior, 77(1), 93-103.

DOI:10.1016/j.jvb.2010.02.009

Byrne, B. M. (2010). Structural equation modeling with AMOS: Basic concepts, applications, and programming. New York: Routledge.

Cagliano, R., Caniato, F., Longoni, A., \& Spina, G. (2014). Alternative uses of temporary work and new forms of work organization. Production Planning and Control, 25(9), 762782. DOI:10.14254/2071-8330.2016/9-1/17

Chambel, M.J., \& Sobral, F. (2011). Training is an investment with return in temporary workers: A social exchange perspective. Career Development International, 16(2), 161- 
Sobral, F., Chambel, M. J., Castanheira, F., \& Cesário, F. (2019). A psychometric assessment of a human resources practice measure for temporary agency workers. Spanish Journal of Psychology, 22, [e16].

\section{DOI: $10.1108 / 13620431111115613$}

Chambel, M.J., Castanheira, F., \& Sobral, F. (2016). Temporary agency versus permanent workers: A multigroup analysis of associations between human resource management, work engagement and affective commitment. Economic and Industrial Democracy, 37(4), 665689. DOI: $10.1177 / 0143831 X 14550695$

Cheung, G.W. \& Rensvold, R.B. (2002). Evaluating goodness-of-fit indexes for testing measurement invariance. Structural Equation Modeling, 9(2), 233-255.

DOI:10.1207/S15328007SEM0902_5

De Cuyper, N., De Witte, H., \& Emmerik, H. V. (2011). Temporary employment: Costs and benefits for (the careers of) employees and organizations. Career Development International, 16(2), 104-113. DOI: 10.1108/13620431111115587

De Jong, J. (2014). Externalization motives and temporary versus permanent employee psychological well-being: A multilevel analysis. European Journal of Work and Organizational Psychology, 23(6), 803-815. DOI:10.1080/1359432x.2013.818217

Den Hartog, Boon, D.N., Verburg, C. \& Croon, R.M. (2013). HRM, communication, satisfaction, and perceived performance: A cross-level test. Journal of Management, 39(6), 1637-1665. DOI:10.1177/0149206312440118

Downing, S.M. (2003). Validity: on the meaningful interpretation of assessment data. Medical Education, 37(9), 830-837.

Eurostat (2016). http://epp.eurostat.ec.europa.eu.

Field, A.P. (2013). Discovering statistics using IBM SPSS Statistics (4 ${ }^{\text {th }}$ ed.). London: Sage. George, E., Levenson, A., Finegold, D., \& Chattopadhyaya, P. (2010). Extra-role behaviors among temporary workers: how firms create relational wealth in the United States of America. The International Journal of Human Resource Management, 21(4), 530-550.

DOI: $10.1080 / 09585191003612034$ 
Sobral, F., Chambel, M. J., Castanheira, F., \& Cesário, F. (2019). A psychometric assessment of a human resources practice measure for temporary agency workers. Spanish Journal of Psychology, 22, [e16].

https://doi.org/10.1017/sjp.2019.18

Gerbing, D.W. \& Hamilton, J.G. (1996). Viability of exploratory factor analysis as a precursor to confirmatory factor analysis. Structural Equation Modeling, 3(1), 62-72. DOI: $10.1080 / 10705519609540030$

Guest, D. (2017). Human resource management and employee well-being: towards a new analytic framework. Human Resource Management Journal, 27(1), 22-38.

DOI:10.1111/1748-8583.12139

Halbesleben, J.R., \& Clark, S.K. (2010). The experience of alienation among temporary workers in high-skill jobs: a qualitative analysis of temporary firefighters. Journal of Managerial Issues, 22(4) 531-545.

Höge, T., Sora, B., Weber, W.G., Peiró, J.M., \& Caballer, A. (2015). Job insecurity, worries about the future, and somatic complaints in two economic and cultural contexts: A study in Spain and Austria. International Journal of Stress Management, 22(3), 223-242.

DOI:10.1037/a0039164

Jiang, J., \& Wang, R. (2018). Want engaged temporary agency workers? Think Beyond the money. Social Behavior Personality, 46(6), 1029-1042. DOI: 10.2224/sbp.7067

Jöreskog, K.G. (2007). Factor Analysis and Its Extensions. In R. Cydeck \& R.C. MacCallum (Ed.), Factor Analysis at 100. Historical Developments and Future Directions (pp. 47-77). Mahwah, New Jersey: Lawrence Erlbaum Associates, Publishers.

Messick, S. (1995). Validity of Psychological Assessment: Validation of inferences from Person's responses and performances as scientific inquiry into score meaning. American Psychologist, 50(9), 741-749. DOI:10.1037/0003-066X.50.9.741

Meyer J.P., Allen, N.J., \& Smith C. (1993). Commitment to organizations and occupations: extension and test of a three-component conceptualization. Journal of Applied Psychology, 78(4), 538-551. DOI: 10.1037/0021-9010.78.4.538

Nishii, L.H., \& Wright, P.M. (2008). Variability within organizations: Implications for 
Sobral, F., Chambel, M. J., Castanheira, F., \& Cesário, F. (2019). A psychometric assessment of a human resources practice measure for temporary agency workers. Spanish Journal of Psychology, 22, [e16]. https://doi.org/10.1017/sjp.2019.18

strategic human resources management. In D. B. Smith (Ed.), LEA's organization and management series. The people make the place: Dynamic linkages between individuals and organizations (pp. 225-248). New York, NY: Taylor \& Francis Group/Lawrence Erlbaum Associates.

OECD (2016). http://www.oecd.org/statistics.

Podsakoff, P.M., MacKenzie, S.B., Lee, J.Y., \& Podsakoff, N.P. (2003). Common method biases in behavioral research: A critical review of the literature and recommended remedies. Journal of Applied Psychology, 88(5), 879-903. DOI: 10.1037/0021-9010.88.5.879

Sobral, F., Chambel, M.J., \& Castanheira (2016). Managing motivation in the contact center: the employment relation of outsourcing and temporary agency workers. Economic and Industrial Democracy, 1-25. DOI:10.1177/0143831X16648386

Sobral, F., Lopes, S., Chambel, M.J., \& Castanheira, F. (2015). A motivation profile analysis: The case of temporary agency work. In M.J. Chambel, (Ed.), The self-determination theory applied to the new work arrangements (pp. 23-56). New York: Nova Publishers.

Tabachnick, B.G. \& Fidell, L.S. (2001). Using Multivariate Statistics. Boston: Allyn and Bacon.

Takeuchi, R., Lepak D.P., Wang, H., \& Takeuchi, K. (2007). An empirical examination of the mechanisms mediating between high performance work systems and the performance of Japanese organizations. Journal of Applied Psychology, 92(4), 1069-1083.

DOI:10.1037/0021-9010.92.4.1069

Ulrich, D., Younger, J., \& Brockbank, W. (2008). The twenty-first-century HR organization, Human Resource Management, 47(4), 829-850. DOI: 10.1002/hrm.20247

WEC, World Employment Confederation 2018), Economic Report 2018 Edition, WEC, Brussels.

Zacharatos, A., Barling, J., \& Iverson, R. D. (2005). High-performance work systems and 
Sobral, F., Chambel, M. J., Castanheira, F., \& Cesário, F. (2019). A psychometric assessment of a human resources practice measure for temporary agency workers. Spanish Journal of Psychology, 22, [e16].

https://doi.org/10.1017/sjp.2019.18

occupational safety. Journal of Applied Psychology, 90(1), 77-93. DOI:10.1037/00219010.90.1.77

Zimmerman, T., Gavrilova-Aguilar, M., \& Cullum, P. (2013). Rethinking Human Resource Strategies: A Shift in the Treatment of Contingent Workers. International Journal of Business and Management, 8(7), 28-34. DOI: 10.5539/ijbm.v8n7p28 
Sobral, F., Chambel, M. J., Castanheira, F., \& Cesário, F. (2019). A psychometric assessment of a human resources practice measure for temporary agency workers. Spanish Journal of Psychology, 22, [e16].

https://doi.org/10.1017/sjp.2019.18

Figure 1. Confirmatory factor analysis model, with one latent factor

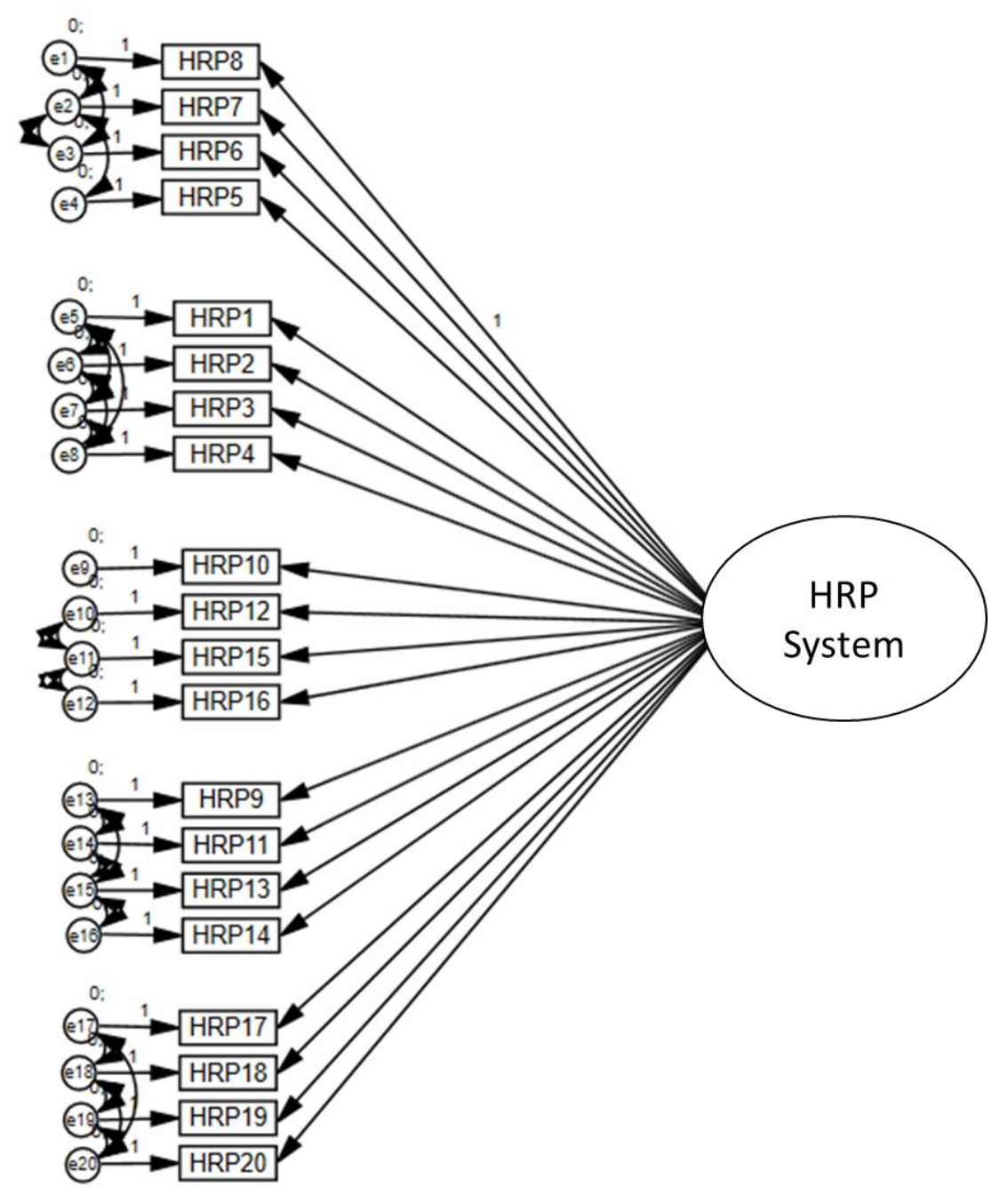

Note: HRP: Human Resources Practices. 
Sobral, F., Chambel, M. J., Castanheira, F., \& Cesário, F. (2019). A psychometric assessment of a human resources practice measure for temporary agency workers. Spanish Journal of Psychology, 22, [e16].

https://doi.org/10.1017/sjp.2019.18

Table 1. Descriptive statistics and correlations

\begin{tabular}{lcccc}
\hline & Mean (SD) & $\begin{array}{c}\text { Cronbach's } \\
\text { alpha }\end{array}$ & 1. & 2. \\
\hline 1. HRP & $4.89(1.17)$ & .94 & & \\
2. ACA & $3.92(1.53)$ & .89 & $.45^{*}$ & \\
3. ACC & $4.47(1.50)$ & .90 & $.52^{*}$ & $.54^{*}$ \\
\hline
\end{tabular}

Note: ACA: AC toward the agency; ACC: AC toward the client company; *p $p .01 ; n=4551$ 
Table 2. HRP scale items

\begin{tabular}{|c|c|c|c|c|c|c|c|c|c|c|}
\hline & \multirow[b]{2}{*}{ Mean (SD) } & \multicolumn{7}{|c|}{ Item difficulty $(\%)$} & \multirow[b]{2}{*}{ Item Disc. } & \multirow[b]{2}{*}{ Factor $1^{*}$} \\
\hline & & 1 & 2 & 3 & 4 & 5 & 6 & 7 & & \\
\hline $\begin{array}{l}\text { 1. When I started working at this company, my line } \\
\text { manager provided support and an initial follow-up. }\end{array}$ & $5.18(1.66)$ & 5 & 5.6 & 5.1 & 10.2 & 20.1 & 32.6 & 21.3 & .63 & .69 \\
\hline $\begin{array}{l}\text { 2. When I started working at this company, I had } \\
\text { information about the goals I had to achieve when } \\
\text { performing my duties. }\end{array}$ & $5.44(1.55)$ & 3.6 & 3.7 & 4.9 & 8.5 & 17 & 36.4 & 25.8 & .64 & .72 \\
\hline $\begin{array}{l}\text { 3. When I started working at this company, my colleagues } \\
\text { gave me support and made me feel integrated. }\end{array}$ & $5.66(1.38)$ & 2.4 & 2 & 2.8 & 9.2 & 17.5 & 35.8 & 30.3 & .53 & .58 \\
\hline $\begin{array}{l}\text { 4. When I started working at this company, I received the } \\
\text { necessary training to perform my duties. }\end{array}$ & $5.25(1.72)$ & 6.1 & 4.2 & 5.5 & 9.7 & 17.3 & 31.6 & 25.7 & .64 & .68 \\
\hline $\begin{array}{l}\text { 5. I performed selection tests (e.g., interview and/or tests) } \\
\text { before I started working at this company. }\end{array}$ & $5.59(1.74)$ & 6.4 & 3.8 & 2 & 8.3 & 10.5 & 30.4 & 38.7 & .43 & .43 \\
\hline $\begin{array}{l}\text { 6. When I was selected to work with this company, my } \\
\text { knowledge and/or previous experiences were taken into } \\
\text { consideration. }\end{array}$ & $5.28(1.69)$ & 5.7 & 4.1 & 3 & 15.9 & 12.7 & 31.9 & 26.8 & .51 & .55 \\
\hline $\begin{array}{l}\text { 7. When I was selected to work at this company, my } \\
\text { knowledge and competences where properly evaluated. }\end{array}$ & $4.97(1.70)$ & 6.5 & 4.7 & 4.5 & 20.5 & 15.1 & 30.7 & 18 & .66 & .68 \\
\hline $\begin{array}{l}\text { 8. When I was selected to work at this company, my } \\
\text { specific knowledge was analyzed. }\end{array}$ & $4.74(1.74)$ & 7.4 & 6.7 & 6 & 20.9 & 17.1 & 27.3 & 14.5 & .61 & .64 \\
\hline $\begin{array}{l}\text { 9. The training I received has made me versatile, increasing } \\
\text { my value in the labor market in a general way. }\end{array}$ & $4.9(1.73)$ & 7.2 & 5.4 & 4.1 & 19.5 & 18.2 & 27.9 & 17.6 & .66 & .71 \\
\hline $\begin{array}{l}\text { 10. I received experience/training that will help me to keep } \\
\text { working at this company where I am now. }\end{array}$ & 4.95 (1.69) & 7 & 4.5 & 4.5 & 18 & 18.8 & 30.7 & 16.4 & .75 & .79 \\
\hline $\begin{array}{l}\text { 11. The experience/training that I have received from the } \\
\text { temporary work has increased the likelihood of being } \\
\text { employed. }\end{array}$ & 4.88 (1.66) & 6.9 & 4.5 & 4.7 & 19.8 & 19.7 & 30.1 & 14.2 & .74 & .77 \\
\hline
\end{tabular}


Sobral, F., Chambel, M. J., Castanheira, F., \& Cesário, F. (2019). A psychometric assessment of a human resources practice measure for temporary agency workers. Spanish Journal of Psychology, 22, [e16]. https://doi.org/10.1017/sip.2019.18

12. With the experience/training that I have received, I can easily change jobs inside the company I am in now.

13. With the experience/training that I have received, it will be easier to find a job.

14. The experience/training I have received through temporary work will allow me to get a better job with a direct contract.

15. The experience/training that I have received increased my value in this company and the chances of getting a direct contract

16. The training I have received will help me to better perform my duties within this company.

17. The performance assessment criteria are clear in this company.

18. If there are flaws in the performance, there is a follow up to overcome them.

19. My supervisor informs me about the goals I must achieve when performing my duties.

20. My supervisor informs me about the performance assessment criteria.

\begin{tabular}{|c|c|c|c|c|c|c|c|c|c|}
\hline $4.35(1.79)$ & 11.2 & 7.8 & 6.9 & 24.9 & 18.3 & 20.8 & 10.3 & .65 & .69 \\
\hline $4.46(1.66)$ & 8.8 & 6.1 & 6.5 & 26.9 & 21.4 & 21.4 & 8.9 & .70 & .73 \\
\hline $4.09(1.66)$ & 11.3 & 7.9 & 7.9 & 34.1 & 17.7 & 14.8 & 6.3 & .62 & .66 \\
\hline $4.25(1.77)$ & 12 & 7.8 & 6.6 & 27.3 & 18 & 19.7 & 8.6 & .67 & .71 \\
\hline $4.73(1.70)$ & 8 & 5.2 & 5.2 & 22 & 20 & 26.6 & 13 & .74 & .77 \\
\hline $4.48(1.83)$ & 10.7 & 7 & 7.7 & 22.8 & 15.8 & 23.1 & 13 & .74 & .78 \\
\hline $4.65(1.73)$ & 8.1 & 6.1 & 7.4 & 21.3 & 18.9 & 25.1 & 13.2 & .77 & .80 \\
\hline $5.16(1.69)$ & 6.1 & 3.9 & 4.4 & 15 & 17.5 & 30.3 & 22.9 & .69 & .73 \\
\hline $4.75(1.86)$ & 9.8 & 6 & 5.3 & 19.9 & 15.5 & 24.8 & 18.7 & .67 & .72 \\
\hline & & & & & \multicolumn{4}{|c|}{$\%$ Variance Explained } & $48.48 \%$ \\
\hline
\end{tabular}

Note $:$ Item disc.$=$ Item Discrimination; $n=4551$

${ }^{*}$ Exploratory factor analysis with a random sample of approximately $50 \%$ of all cases $(n=2273)$ 
Sobral, F., Chambel, M. J., Castanheira, F., \& Cesário, F. (2019). A psychometric assessment of a human resources practice measure for temporary agency workers. Spanish Journal of Psychology, 22, [e16]. https://doi.org/10.1017/sjp.2019.18

Table 3. Fit statistic for the measurement of HRP system of TAW

\begin{tabular}{|c|c|c|c|c|c|c|c|c|c|c|}
\hline Models & $\mathrm{N}$ & $\chi^{2}$ & $d f$ & $p$ & $\Delta \chi^{2}$ & SRMR & CFI & TLI & $\Delta \mathrm{CFI}$ & RMSEA \\
\hline Services Sample & 3129 & 3626.61 & 149 & .00 & -- & .07 & .92 & .90 & -- & .09 \\
\hline Industry Sample & 1399 & 1604.38 & 149 & .00 & -- & .06 & .93 & .91 & -- & .08 \\
\hline $\begin{array}{l}\text { Baseline Model } \\
\text { (Two sectors combined) }\end{array}$ & 4551 & 5230.98 & 298 & .00 & -- & .07 & 92 & .90 & -- & .06 \\
\hline Full Constrained Model & 4551 & 6017.16 & 379 & .00 & $\begin{array}{l}\text { Compare Baseline Model } \\
\Delta \chi^{2}=786.18^{* *} ; \mathrm{df}=81\end{array}$ & .07 & .92 & .90 & .00 & .06 \\
\hline $\begin{array}{l}\text { Measurement Model } \\
\text { Invariant (Factor loadings) }\end{array}$ & 4551 & 5259.01 & 317 & .00 & $\begin{array}{l}\text { Compare Baseline Model } \\
\qquad \Delta \chi^{2}=28^{\mathrm{ns}} ; \mathrm{df}=19\end{array}$ & .07 & 92 & .90 & .00 & .06 \\
\hline
\end{tabular}

Note: df: degree of freedom; SRMR: Standardized root mean square; CFI: Bentler comparative fit index; TLI: Tuckler Lewis index; RMSEA: root mean square error of approximation; ns: non-significant; ${ }^{* *} p<.001$. 